\title{
Power Transformer Wire Estimate
}

\author{
Angelo B. Dalaguit ${ }^{1} \&$ Mary Ann L. Dalaguit ${ }^{1}$ \\ ${ }^{1}$ Cebu Technological University San Francisco Campus, San Francisco, Cebu, Philippines \\ Correspondence: Angelo B. Dalaguit, Cebu Technological University San Francisco Campus, San Francisco, \\ Cebu, Philippines 6050.
}

Received: December 29, 2016

Accepted: January 21, $2017 \quad$ Online Published: February 20, 2017

doi:10.20849/aes.v2i1.112

URL: http://dx.doi.org/10.20849/aes.v2i1.112

\begin{abstract}
This experimental study determined the weight of wire used in power supply using the laboratory technique and procedure to gather data. There were two designs with three treatments each, prepared and subjected to using the Two Way Analysis of Variance. The treatments for the first design were: one is $11 / 8$ inch by $11 / 8$ inch area and output voltage of 6 volts; two is $11 / 8$ inch by $11 / 8$ inch area and output voltage of 36 volts; three is $11 / 8$ inch by $11 / 8$ inch area and output voltage of 110 volts. The treatments for design number two were: one is $1 / 2$ inch by $1 / 2$ inch area and output voltage of 12 volts; two is $3 / 4$ inch by $3 / 4$ inch area and output voltage of 12 volts; three is 1 inch by 1 inch area and output voltage of 12 volts. The test result of significant differences in the effectiveness, efficiency and performance of the different treatments showed no significant difference on windings, temperature, voltage, size of the iron core, current, power, number of turns, turns per volt and force applied in winding.
\end{abstract}

Keywords: power supply transformer, output voltage, number of turns

\section{Introduction}

Transformer is an electrical device used to transfer electrical energy from one circuit to another circuit by means of electro-magnetic induction. The primary circuit and the secondary circuit are interlinked by a magnetic circuit which is called iron core. In the transfer of electrical energy, the original form of the voltage and the current is changed into a different characteristic. When the voltage is increased, the current is decreased and vice-versa.

Power Transformers are used widely in electronic products to step down the source at a level to which needed by the circuit. Power transformer also electrically isolates the end user from contact with the supply voltage (http://en. wikipedia.org/wiki/Transformer. January 2008).

In the construction of a power supply transformer, constructors usually find difficulty because of the absence of a wire estimate in terms of weight from the original design. It is in this context that this research is conducted to determine the weight of wire to be used in power supply making. This is an important part of constructing a power transformer especially to the beginners who need guidance in purchasing the different materials needed. The result of this study can be used not only for the beginners but also for all makers of transformer. Predetermination of the amount of magnetic wire used for the construction of transformers is in line with the conservation measures of the government to minimize or possibly avoid waste. This study guides the proper ratio of magnetic wire in terms of weight in grams in the production of power supply transformer.

Normally all transformers are closely related to its number of turns. But it does not mean that the precise numbers of turns of a conductor are the bases to establish the equivalent voltage and current. The important is the specific ratio of turns. For example, a transformer with two coils: a 1,000 turns of conductor in the primary coil and 250 turns of conductor in the secondary coil could have 4 is to 1 , or 4:1 $(1,000 / 250=4)$ which point out that for every four turns of a conductor in the primary coil, one turn equivalent in the secondary coil (Herman, 1999).

Transformer comes from the word transform which means to change. The pressure that drives an electrical current through a wire is called voltage. A transformer changes the voltage from low to high or from high to low. It also changes the current in the same way. A transformer that increases voltage is called step-up transformer while the one that decrease voltage is step-down transformer. The action of transformers makes electricity available at whatever voltage is needed to do a particular job. Transformers also make it possible to transmit electricity over long distance efficiently (Spies, 2007). 
Grob (1993) declared that transformer is an important application of mutual inductance. The purpose of the transformer is to transfer power from the primary, where the generator is connected to the secondary. The transformer is used to provide power to the load resistance instead of connecting directly across the generator, whenever the load requires an alternating current voltage higher or lower than the generator voltage.

Pagarigan and Bandi (1986) explained that the power transformer is a major component used in most electronic devices. It can be considered the heart of the equipment. Transistor and integrated circuit operate on lower voltage than the one in the outlet. Reducing the line voltage is the function of the transformer. The transformer also isolates the chassis from the AC line. The primary and the secondary of the transformer are designed to comply with the different demand of the circuit.

Faina (2000) said a transformer is an alternating current-voltage changing devices, by means of which electricity can be received at one voltage and deliver at another voltage either higher or lower. Usually consists of two separate coils on an iron core: one, which receives power called the primary coil; while the other that delivers the power is called the secondary coil. The type of voltage and current supplied by power companies is an alternating (AC). Literally, AC means alternating current. But in electronics and electrical technology, it is a standard practice to call this type of voltage and current as AC voltage and AC current. When AC is made to flow through a coil of wire, the said coil of wire becomes an artificial electromagnet. This electromagnet exhibits all the properties of a permanent magnet, such the power of attraction and repulsion by means of its magnetic lines of force, which induces corresponding voltage or current proportional to the ratio of the primary and secondary turns of the transformer.

The power supply is the heart of all electronic equipment or appliances. It supplies the electronic equipment all the voltages and current needed for its normal operation. One type of power supply is the converter. Basically the converter power supply is a type of supply that converts one type of voltage and current to another type (Faina 1991 ), and one of the major parts of a power supply is a transformer.

Barba (2006) stated that transformer is an electrical or electronic device, without any moving parts, that produce electrical energy through electromagnetic induction. Through mutual inductance, the current in the primary winding induced current to the secondary winding. Auto transformer is one which windings are shared; primary windings are connected to the secondary windings in order to reduce the size of the transformer. The disadvantage of the auto transformer is that the two windings are not isolated.

The material use in constructing a power transformer core determines the function as to voltage, current, power and frequency. The size, limitations and fabrication costs are also factors to be measured. Mostly core materials use are air, soft iron, and steel. Each of these materials is appropriate for particular purposes and is not for others. The air-core transformers are used for a high voltage frequency (above $20 \mathrm{kHz}$ ). The iron-core transformer is used when the source frequency is low (below $20 \mathrm{kHz}$ ). The soft-iron-core transformer is appropriate to a physically small but efficient transformer. The iron-core transformer induces a better power than the air-core transformer. A transformer whose core is fabricated of laminated sheets of steel drive away heat readily; thus it offers capable transfer of power. The important point is that the most efficient transformer core is one that offers the best path for the most lines of flux with the least loss in magnetic and electrical energy, (http://www.sayedsaad.com/fundamental/19_ Transformers \%20.htm. April 2008).

A best transformer has no power losses, so therefore $100 \%$ efficient. However, the most efficient transformer for electrical machines are those design using superconducting coils that achieve efficiencies of $99.85 \%$, energy is dissipated in the coils, iron core and the environment. Large power transformers are normally more efficient, those rated for electricity distribution usually carry out better than $95 \%$. Small transformer, like plug-in that is used for low-power consumer electronics, may be not more than $85 \%$ efficient. Power transformer losses are recognized by different reasons and distinguished between those originating in the coils, sometimes termed copper losses, and those came from the magnetic circuit, sometimes termed iron loss. Winding resistance controls load losses, whereas hysteresis and eddy currents losses contribute to over $99 \%$ of the no-load loss. The no-load loss can be significant, even those transformer not in used constitutes a drain that lead to the development of low-loss transformer (http://en. wikipedia.org/wiki/Transformer. January 2008).

\section{Material and Methods}

\subsection{Method Used}

The experimental method of research was used in conducting the study. It employed the laboratory techniques and procedures. 
The main purpose of this study was to determine the weight of magnetic wire to be used in power supply construction, through the use of an isolation type of transformer. This could be a basis for the formulation of a technology guide. Specifically, the study experimented on the following designs:

\subsection{Materials}

1). Design number one: the same area of bobbin with different voltage output

1.1). treatment 1 : area is $11 / 8$ inch by $11 / 8$ inch and the output voltage is 6 volts

1.2). treatment 2 : area is $11 / 8$ inch by $11 / 8$ inch and the output voltage is 36 volts

1.3). treatment 3 : area is $11 / 8$ inch by $11 / 8$ inch and the output voltage is 110 volts

2). Design number two: the same voltage output with different area of bobbin

2.1). treatment 1 : area is $1 / 2$ inch by $1 / 2$ inch and the output voltage is 12 volts

2.2). treatment 2 : area is $3 / 4$ inch by $3 / 4$ inch and the output voltage is 12 volts

2.3). treatment 3: area is 1 inch by 1 inch and the output voltage is 12 volts

There were two designs with three treatments, each was prepared and intended for testing and analysis. The same materials, tools, equipment and procedures were done throughout the experiment. Three replications were made in order to arrive at the most consistent outcome from the two designs. Samples were marked prior to the different designs and subject for ohmmeter and voltmeter testing.

The data were subjected to statistical analysis for interpretation using the Analysis of Variance (ANOVA). The function was determined by providing input voltage in the primary windings and testing the output voltage by the use of voltmeter.

\section{Results and Discussion}

\section{Effectiveness of Wire Estimate Computation for Design Number One and Two}

\section{Effectiveness of Wire Estimate Computation in the Primary Windings for Design Number One}

Based in all the treatments, the mean increment indicates very effective results. This implies that the formulation to determine the amount of wire used for the primary windings was utilized very effectively. In all the treatments for replicate one, two and three, the computed weight was 82 grams, because in design number one for primary winding the area of bobbin was constant which was equal to $11 / 8$ inch by $11 / 8$ inch and the input voltage is 220 volts based on the standard voltage from the electric company. Computed weight was the calculated weight of wire based on the result of the computation. The actual weight in treatment one for replicate one and two were 71 grams, and for replicate three was 70 grams. Treatment two for replicate one, two and three were 70 grams. Treatment three for replicate one and three were 71 grams and replicate two was 70 grams. Actual weight was the weight of wire used in the power transformer and differs due to the arrangement of wire during winding. The increment in treatment one for replicate one and two were 11 grams and 12 grams for replicate three. Treatment two for replicate one, two and three were 12 grams. Treatment three for replicate one and three were 11 grams and replicate two was 12 grams. Increment was the difference of weight between the actual weight and the computed weight while mean increment was the mean difference of replicate one, two and three.

\section{Effectiveness of Wire Estimate Computation in the Secondary Windings for Design Number One}

Based in the mean increment, the decision was very effective for the treatments. This implies that the formulation developed was used very effectively for estimating the amount of wire to be used for the secondary windings in making transformer. The computed weight in treatment one for replicate one, two and three were 82 grams; treatment two for replicate one, two and three were 97 grams and treatment three for replicate one, two and three were 93 grams. All treatments differ in the computed weight because it depends upon the output voltage which for treatment one was 6 volts, treatment two was 36 volts and for the treatment three was 110 volts. Computed weight was the calculated weight of wire based on the result of the computation. The actual weight in treatment one for replicate one was 71 grams, for replicate two was 70 grams and for replicate three was 72 grams. Treatment two for replicate one was 79 grams, for replicate two and three were 80 grams. Treatment three for replicate one and three were 78 grams and replicate two was 77 grams. Actual weight was the weight of wire used in the power transformer and differs in the three treatments due to the different voltage output and the arrangement of wire during winding. The increment in treatment one for replicate one was 11 grams, for replicate two was 12 grams and for replicate three was 10 grams. Treatment two for replicate one was 18 grams, for replicate two and three were 17 grams. Treatment three for replicate one and three were 15 grams and replicate two was 16 grams. Increment was 
the difference of weight between the actual weight and the computed weight while mean increment was the mean difference of replicate one, two and three.

\section{Effectiveness of Wire Estimate Computation in the Primary Windings for Design Number Two}

All treatments resulted to very much effective. This entails that the developed formula was very much effective to estimate the amount of wire for transformer computation. The computed weight in treatment one for replicate one, two and three were 14 grams; treatment two for replicate one, two and three were 36 grams and treatment three for replicate one, two and three were 67 grams. All treatments differ in the computed weight since the input voltage was 220 volts but the area of bobbin was different; for treatment one was $1 / 2$ inch by $1 / 2$ half inch, treatment two was $3 / 4$ inch by $3 / 4$ inch and treatment three was 1 inch by 1 inch, therefore it depends upon also the area of the bobbin. Computed weight was the calculated weight of wire based on the result of the computation. The actual weight in treatment one was 14 grams for replicate one, two and three. Treatment two for replicate one was 31 grams, for replicate two and three were 30 grams. Treatment three for replicate one and three were 60 grams and replicate two was 59 grams. Actual weight was the weight of wire used in the power transformer and differs in the three treatments due to the different area of bobbin and the arrangement of wire during winding. The increment in treatment one for replicate one, two and three were 0 . Treatment two for replicate one was 5 grams, for replicate two and three were 6 grams. Treatment three for replicate one and three were 7 grams and replicate two was 8 grams. Increment was the difference of weight between the actual weight and the computed weight while mean increment was the mean difference of replicate one, two and three.

\section{Effectiveness of Wire Estimate Computation in the Secondary for Design Number Two}

Based on the mean increment the decision was very much effective. This denotes that the developed formula was very much effective in determining the amount of wire for the secondary windings for different sizes of bobbin with the same voltage output. The computed weight in treatment one for replicate one, two and three were 14 grams; treatment two for replicate one, two and three were 45 grams and treatment three for replicate one, two and three were 85 grams. All treatments differ in the computed weight since the output voltage was 12 volts but the area of bobbin was different; for treatment one was $1 / 2$ inch by $1 / 2$ half inch, treatment two was $3 / 4$ inch by $3 / 4$ inch and treatment three was 1 inch by 1 inch, therefore it depends upon also the area of the bobbin. Computed weight was the calculated weight of wire based on the result of the computation. The actual weight in treatment one was 14 grams for replicate one, two and three. Treatment two for replicate one and three was 41 grams, for replicate two was 42 grams. Treatment three for replicate one was 77 grams, replicate two was 80 grams and replicate three 79 grams. Actual weight was the weight of wire used in the power transformer and differs in the three treatments due to the different area of bobbin and the arrangement of wire during winding. The increment in treatment one for replicate one, two and three were 0 . Treatment two for replicate one and three were 4 grams and replicate two was 3 grams. Treatment three for replicate one was 8 grams, replicate two was 5 grams and replicate three was 6 grams. Increment was the difference of weight between the actual weight and the computed weight while mean increment was the mean difference of replicate one, two and three.

\section{Efficiency of Wire Estimate Computation for Design Number One and Two Efficiency of Wire Estimate Computation for Design Number One}

Based on ambient temperature the decision was normal for the three treatments. This indicates that the developed formula was efficient for design number one which was composed of the same area of bobbin, $11 / 8$ inch by $11 / 8$ inch and the length of time during testing was 10 minutes. Treatment one for replicate one, the temperature was $33^{\circ} \mathrm{C}$ and for replicate two and three were $32^{\circ} \mathrm{C}$, the mean temperature was $32^{\circ} \mathrm{C}$ and the decision was normal. Treatment two for replicate three the temperature was $33^{\circ} \mathrm{C}$ and for replicate one and two were $32^{\circ} \mathrm{C}$, the mean temperature was $32^{\circ} \mathrm{C}$ and the decision was normal. Treatment three for replicate one the temperature was $32^{\circ} \mathrm{C}$, replicate two the temperature was $33^{\circ} \mathrm{C}$ and replicate three the temperature was $34^{\circ} \mathrm{C}$, the mean temperature was $33^{\circ} \mathrm{C}$ and the decision was normal.

\section{Efficiency of Wire Estimate Computation for Design Number Two}

Based on ambient temperature the decision was normal for the three treatments. This indicates that the developed formula was efficient for design number two which was composed of the same voltage output, 12 volts with different area of bobbin and the length of time during testing was 10 minutes. Treatment one for replicate one the temperature was $34^{\circ} \mathrm{C}$, for replicate two the temperature was $32^{\circ} \mathrm{C}$ and for replicate three was $35^{\circ} \mathrm{C}$, the mean temperature was $34^{\circ} \mathrm{C}$ and the decision was normal. Treatment two for replicate one, two and three the temperature was $33^{\circ} \mathrm{C}$, the mean temperature was $33^{\circ} \mathrm{C}$ and the decision was normal. Treatment three for replicate one the 
temperature was $32^{\circ} \mathrm{C}$, replicate two the temperature was $33^{\circ} \mathrm{C}$ and replicate three the temperature was $32^{\circ} \mathrm{C}$, the mean temperature was $32^{\circ} \mathrm{C}$ and the decision was normal.

\section{Performance of the Treatments for Design Number One and Two}

\section{Performance Output of the Treatments in the Primary Windings for Design Number One}

All treatments disclose the same input voltage, area of the bobbin, current, power, number of turns, turns per volt and force applied during winding. This entails that the performance output of the transformers made was the same as the computed output in terms of voltage, iron core, current, power, number of turns, turns per volt. The force applied was the same to all treatments because of the magnetic wire which was Number 31 in all the treatments. Treatment one, two and three the voltage was 220 volts because that was the input voltage and it was standard from the service provider. For current, power, number of turns and turns per volt in all the treatments were the same because the area of bobbin for treatment one, two and three were constant.

\section{Performance Output of the Treatments in the Secondary Windings for Design Number One}

The performance of the secondary windings with the same area of bobbin expresses constant power and turns per volt of the entire transformer. As shown in the table it was found out that there was an increase of voltage output, while current and the force applied during winding decreased. This implies that as the output voltage increased, current and force applied decreased and number of turns increased. Treatment one, two and three for turns per volt was constant because that was based on the area and power which was fixed in all the treatments. Treatment one the output voltage was 6 volts, current was 4.2 amperes, for power that was 25 watts in which that was constant for the entire transformer, the number of turns was 36 turns and the applied forced during winding was 3 Newtons. Treatment two, the output voltage was 36 volts, current was .69 ampere, the number of turns was 216 turns and the applied forced during winding was 2.5 Newtons. Treatment three, the output voltage was 110 volts, current was .23 ampere, the number of turns was 660 turns and the applied forced during winding was 2 Newtons.

\section{Performance Output of the Treatments in the Primary Windings for Design Number Two}

Displays the same input voltages of all the treatments, but all other areas differ from one another. This means that as area of the bobbin increased there was also an increase of current, power and the force applied in the wire during winding. There was a decrease of the number of turns and turns per volts as the area of bobbin increased. Treatment one, the area was $1 / 2$ inch by $1 / 2$ inch, current was .014 ampere, power was 3 watts, the number of turns was 3960 turns, turns per volt was 18 turns and the forced applied during winding was .5 Newton. Treatment two, the area was $3 / 4$ inch by $3 / 4$ inch, current was .045 ampere, power was 10 watts, the number of turns was 2200 turns, turns per volt was 10 turns and the forced applied during winding was .75 Newton. Treatment three, the area was 1 inch by 1 inch, current was .091 ampere, power was 20 watts, the number of turns was 1540 turns, turns per volt was 7 turns and the forced applied during winding was 1.5 Newton.

\section{Performance Output of the Treatments in the Secondary Windings for Design Number Two}

This illustrates the same output voltage of all the treatments with constant power and turns per volt for every treatment. It means that when there is an increase of the area of the bobbin, current, power and force applied in winding increased while number of turns and turns per volt decreased. Treatment one, the output voltage was 12 volts, area was $1 / 2$ inch by $1 / 2$ inch, current was .25 ampere, power was 3 watts, number of turns was 216 turns, turns per volt was 18 turns and the forced applied during winding was 2 Newtons. Treatment two, the output voltage was 12 volts, area was $3 / 4$ inch by $3 / 4$ inch, current was .83 ampere, power was 10 watts, number of turns was 120 turns, turns per volt was 10 turns and the forced applied during winding was 2.75 Newtons. And the last treatment, treatment three, the output voltage was 12 volts, area was 1 inch by 1 inch, current was 1.67 ampere, power was 20 watts, number of turns was 84 turns, turns per volt was 7 turns and the forced applied during winding was 3 Newtons.

\section{Test of the Significant Differences in the Effectiveness and Performance of the Different Treatments}

Effectiveness of Wire Estimate Computation for Primary Windings. The result of testing the significant difference of the treatments based on the effectiveness of wire estimate computation of the primary windings for design number one and two was not significant, because the computed F value of 2.94 was lesser than the table value of 3.3. This implies that the null hypothesis of no significant difference was accepted due to the fact that the computed value was lesser than the table value.

Effectiveness of Wire Estimate Computation for Secondary Windings. Upon testing the significant difference among treatments based on the effectiveness of wire estimate computation of the secondary windings for design number one and two, it was found out that the result was not significant. Hence the tabulated value of 3.3 was 
higher than the computed value of 2.91. This implies that the null hypothesis of no significant difference was accepted because the computed value was lesser than the table value.

Efficiency Based on Temperature. The result of this illustrates no significant difference for the efficiency based on temperature. Since the tabulated $\mathrm{F}$ value of 3.3 was higher than the calculated $\mathrm{F}$ value of .51. Thus, the null hypothesis of no significant difference among the treatments was accepted for the reason that the computed value was lesser than the table value.

Performance of Wire Estimate Computation for Primary Voltage. The result of this designates no significant difference for the performance of wire estimate for primary voltage. As the tabulated $\mathrm{F}$ value of 3.3 was higher than the calculated $\mathrm{F}$ value of 0 . Therefore the null hypothesis of no significant difference among the treatments was accepted for the basis that the computed value was lesser than the table value.

Performance of Wire Estimate Computation for Secondary Voltage. This illustrates the output of testing the significant difference of the treatments based on the performance of wire estimate computation of the secondary voltage for design number one and two was not significant, for the reason that the computed $F$ value of 3.00 was lesser than the table value of 3.3. This implies that the null hypothesis of no significant difference was accepted due to the fact that the computed value was lesser than the table value.

Performance of Wire Estimate Computation for the Size of the Iron Core. The outcome of this divulges no significant difference for the performance of wire estimate computation for the size of the iron core. As the computed $\mathrm{F}$ value of 3.00 was lesser than the tabulated $\mathrm{F}$ value 3.3. Therefore, the null hypothesis of no significant difference among the treatments was accepted for the reason that the computed value was lesser than the table value.

Performance of Wire Estimate Computation on Current for the Primary. This gives details that upon testing the significant difference among treatments based on the performance of wire estimate computation on current for the primary for design number one and two, it was established that the result was not significant. Since the tabulated value of 3.3was higher than the computed value of 3.0. This entails that the null hypothesis of no significant difference was accepted because the computed value was lesser than the table value.

Performance of Wire Estimate Computation on Current for the Secondary. The tabulated F value of 3.3 was higher than the calculated $\mathrm{F}$ value of 3.0. Therefore, the null hypothesis of no significant difference among the treatments was accepted for the basis that the computed value was lesser than the table value.

Performance of Wire Estimate Computation for Power. The product of this table delegates no significant difference for the performance of wire estimate computation for power. Based on the tabulated $\mathrm{F}$ value of 3.3 was higher than the calculated $F$ value of 3.00. Thus the null hypothesis of no significantdifference among the treatments was accepted for the basis that the computed value was lesser than the table value.

Performance of Wire Estimate Computation on Number of Turns for Primary Windings. This exhibits the result of testing the significant difference of the treatments based on the performance of wire estimate computation on number of turns for primary windings for design number one and two was not significant, since the computed F value of 3.00 was lesser than the table value of 3.3. This implies that the null hypothesis of no significant difference was accepted because the computed value was lesser than the table value.

Performance of Wire Estimate Computation on Number of Turns for Secondary Windings. There was no significant difference on the performance of wire estimate computation on number of turns for secondary windings, since the computed $\mathrm{F}$ value of 3.00 was lesser than the tabulated $\mathrm{F}$ value of 3.3. Thus the null hypothesis of no significant difference was accepted for the reason that the computed value was lesser than the table value.

Performance of Wire Estimate Computation on Turns per Volt for Primary and Secondary Windings. As observed upon testing the significant difference of the treatments based on the performance of wire estimate computation on turns per volt for primary and secondary windings for design number one and two was not significant, since the tabulated $\mathrm{F}$ value of 3.3 was greater than the computed $\mathrm{F}$ value of 3.00 . This implies that the null hypothesis of no significant difference was accepted because the computed value was lesser than the table value.

Performance of Wire Estimate Computation on Force Applied for Primary Windings. The product proves no significant difference for the performance of wire estimate computation on force applied for primary windings. Since the tabulated $\mathrm{F}$ value of 3.3 was higher than the calculated $\mathrm{F}$ value of 3.00 . Thus, the null hypothesis of no significant difference among the treatments was accepted for the reason that the computed value was lesser than the table value. 
Performance of Wire Estimate Computation on Force Applied for Secondary Windings. This shows that upon testing the significant difference among treatments based on the performance of wire estimate computation on applied force for the secondary windings for design number one and two, it was found out that the result was not significant. Since the tabulated value of 3.3 was higher than the computed value of 3.0. This entails that the null hypothesis of no significant difference was accepted because the computed value was lesser than the table value.

\section{Findings}

Based on the data gathered after thorough analysis, the following findings have been made.

\subsection{Effectiveness of Wire Estimate Computation}

\subsubsection{Primary Windings}

The mean increment on design number 1indicates, very effective results, while very much effective on design number 2 .

\subsubsection{Secondary Windings}

The result found out to be very effective on design number 1 while very much effective on design number 2 .

\subsection{Efficiency Based on Temperature}

4.2.1 The result of this illustrates no significant difference for the efficiency based on temperature. Since the tabulated $\mathrm{F}$ value of 3.3 was higher than the calculated $\mathrm{F}$ value of .51. Thus, the null hypothesis of no significant difference among the treatments was accepted for the reason that the computed value was lesser than the table value.

4.3 Performance of the Treatments for Design Number 1 and 2 on Voltage, Size of the Iron Core, Current, Power, Number of Turns, Turns per Volt and Force Applied in Winding

4.3.1 The performance output of the two designs both in the primary windings and secondary windings revealed identical with that of the computed value.

\subsection{Test of the Significant Differences in the Effectiveness and Performance of the Different Treatments}

\subsubsection{Windings}

There were no significant differences observed among the treatments on primary windings and secondary windings for design 1 and 2 as to effectiveness.

\subsubsection{Temperature}

There was no significant difference observed among the treatments for design 1 and 2 as to efficiency.

\subsubsection{Voltage}

There were no significant differences observed among the treatments on primary voltage and secondary voltage for design 1 and 2 as to performance.

\subsubsection{Size of the Iron Core}

There was no significant difference reflected between treatments on size of the iron core for design 1 and 2 as to performance.

\subsubsection{Current}

There were no significant differences reflected between treatments on current for the primary and current for the secondary for design 1 and 2 as to performance.

\subsubsection{Power}

There were no significant differences reflected between treatments on current for the primary and current for the secondary for design 1 and 2 as to performance.

\subsubsection{Number of Turns}

There were no significant differences observed among the treatments on number of turns for primary windings and number of turns for secondary windings for design 1 and 2 as to performance.

\subsubsection{Turns per Volt}

There was no significant difference observed among the treatments on turns per volt for design 1 and 2 as to performance. 


\section{Conclusion}

Based on the findings, it was concluded that the effectiveness of wire estimate computation was very much effective, while efficiency was normal based on ambient temperature.

The performance of the primary windings and secondary windings of the experimental design gives identical functions, normal temperature and no overheating during testing.

Determining the weight of wire in a transformer rewinding for primary coil and secondary coil during fabrication gives precise supply of magnetic wire to be use in the fabrication of power supply transformer, thus avoiding wastage. This is also beneficial to the environment because it limits the amount of excess conductors that can go to the trash and becomes a non-degradable items leading to environmental pollution.

Formulation of technology guide to disseminate information serves as a guide by the students during transformer construction.

\section{Recommendations}

Based on the findings, the following recommendations are presented for consideration:

1). Conduct further studies to include the weight of the iron core.

2). Use digital weighing scale in finding the weight of wire.

3). Use double coated magnetic wire.

4). Adopt the proposed techno-guide.

\section{References}

Barba, J.A. (2006). Building Utilities Electrical. Mechanical. Acoustic. Andes Mountain Printers Bitano. Legazpi City, p.243.

Faina, J.S. (1991). Practical Electronics Projects and Trouble Shooting (2nd ed.). National Book Store. Quad Alpha Centrum Bldg. 125 Pioneer St., Mandaluyong City, p.105.

Faina, J.S. (2000). Basic Transistorized Amplifiers. (3rd ed.). National Book Store. Quad Alpha Centrum Bldg. 125 Pioneer St., Mandaluyong City, p.295.

Grob, B. (1993). Grob Basic Electronics. (7nd ed.). Echanis Press, Inc.760 Boni Avenue, Mandaluyong, Metro Manila, p.929.

Herman, S.L. (1999). Electrician's Technical Reference Transformer.

Pagarigan, M.S. (1995). Practical Electronics Transformer Rewinding and AM/ FM Servicing. Book 111.Electrolab, 3393 Ramon Magsaysay Blvd., Sta., Mesa Manila, P.115.

Retrieved April 2008, from http://www.sayedsaad.com/fundamental/19_ Transformers \%20.htm

Retrieved January 2008, from http://en.wikipedia.org/wiki/Transformer

Spies, H. (2007). The New Book of Knowledge, Volume 18. Scholastic, Library Publishing, Inc., Danbury, Connecticut, p.402.

\section{Copyrights}

Copyright for this article is retained by the author(s), with first publication rights granted to the journal.

This is an open-access article distributed under the terms and conditions of the Creative Commons Attribution license (http://creativecommons.org/licenses/by/4.0/). 